\title{
Comparing Social Media Reactions to Early Game Songs and Final Boss Music in Single Player Adventure Games
}

\author{
Samuli Laato \\ Gamification Group, Tampere University \\ samuli.laato@tuni.fi
}

\author{
Sampsa Rauti \\ University of Turku \\ sjprau@utu.fi
}

\begin{abstract}
Single player video games unite players through shared experiences, passion and knowledge about the game. We investigated the role of video game music in this setting. We analysed comments $(n=1893)$ on 20 popular single player adventure game songs on social media sorted into four clusters based on the following two variables (1) age of the game; and (2) whether the song appears early on in the game or at the end. We discovered that there are more similarities in the types of comments and sentiments between early game songs across games than between songs from the same game. Early game songs had substantially more comments related to nostalgia, sadness and "feeling of home" compared to late game songs. Comments on late game songs were more focused on players' experiences while playing. Overall, all 20 songs had overwhelmingly more comments on associations (both game and life related) than on the actual song itself.
\end{abstract}

\section{Introduction}

"The use of music to characterize fictional spaces in game environments is obviously more relevant in games revolving around quest narratives." [1]

Adventure video games consist of various components such as audio, visuals, game mechanics, story and narration. The relevance of these elements and how they are utilized are dependent on the game in question. Consequently, video game music also has various use purposes. It can support the game mechanics with rhythm, scaffold or amplify the emotional themes of a story [2, 3] or add meaning to fictional spaces in adventure games [1].

When asked to recall meaningful playing experiences, adolescent players named audiovisual elements including music as one of the key components [4]. Subsequently, the role of music is particularly relevant in reminiscence and nostalgia [5], where hearing a specific song can invoke memories and nostalgic thoughts [6]. Nostalgia is also connected to social memories, relatedness and connectedness [5]. The social component of music is highlighted by the cross-cultural contexts it appears in such as infant-care, dance and love [7]. In order to produce harmonious music, in the past a great deal of cooperation between humans was needed [7]. Music could only be heard in social settings where people were present to produce the music. Recent work has suggested that video game players are united by their common passion for games [8] and knowledge about the fictional world of the games that they play [9]. This further ties social experience to video game music.

While music is an integral part of adventure games (e.g. Pokémon games or the Assassin's Creed series), work on games' soundtracks has seen little attention [3]. In this work we contribute to the research on video game music by focusing on experiences that people share on social media regarding specific video game songs. We chose YouTube as our study context as various video game soundtracks appear there coupled with a comment section. To add a comparison setting in our study, we observe differences between early game songs i.e. songs that appear during the first hour of gameplay, and final boss music i.e. songs that appear during the final boss battles. This approach allows us to explore potential game-induced associations. Furthermore, we selected songs from two different time periods separated by a 10-year time window to explore musical nostalgia [5]. Consequently, we formulate the following three research questions for this study:

RQ1: On which topics do adventure game players focus on when commenting on the game soundtrack on social media?

RQ2: What themes are present in YouTube comments regarding the impact of music in older games versus newer games?

RQ3: What themes are present in YouTube comments regarding early game songs versus the final battle music?

The rest of this paper is structured as follows. First 
we present a brief literature background on music in video games which we follow up by the materials and methods of the empirical work. We then present our results and key findings followed up by the implications of the study, limitations, conclusions and future work.

\section{Background - Music in Video Games}

Most but not all video games contain sounds and music. As discussed, music can perform many tasks in a game from supporting players' emotions [3] to describing the digital space and informing the player of in-game events $[10,1]$. Some games feature songs composed specifically for the game while others borrow existing music. Summers [10] delivers detailed examples of music across popular games in various genres and demonstrates how music can be used for multiple purposes. One of the crucial tasks of music in adventure games is to texture the playing areas, giving meaning to the virtual spaces beyond what visuals offer $[10,1]$. Here music becomes an integral part of the audiovisual narrative of the game - delivering information to the players and supporting their thinking by interpreting the mood and feel of the area the players are in.

Video game music has evolved from being developer-driven and fairly simple to the point where film composers are regularly hired to create game soundtracks [11]. The sound budget of modern video games can be in the millions and world class orchestra may be hired to play on the soundtracks. The quality of video game music can currently be considered completely on par with the rest of commercial music [11]. For example, in 2011 the title song of the game Civilization 4 won a Grammy award [11]. On platforms such as YouTube, video game songs can receive millions of views.

Hart [12] argues that the interaction between songs and the player's freedom to move around is difficult to analyse, as the experience of the music changes based on the player's actions. In addition to players' experiences in-game, their past knowledge and real world situation largely impact the perceptions [12]. Whalen [13] discussed the differences between video game music and film music and argued that generalisations and rigid taxonomies of differences between the two should be avoided, as both video games and films are unique. In light of Whalen's argument, small steps relying on empirical evidence are needed to bring clarity to the role of music in video games.

\section{Materials and methods}

In this work, we observed differences between players' reactions to songs appearing early on (during the first hour of play) in adventure games and songs appearing at the end (i.e. final battle music). We formed two clusters of games based on when they were released to explore potential differences in nostalgic sentiment. The first cluster had games released between 1996-2004 and the second had games released between 2015-2019, meaning the two comparison clusters were roughly 10 years apart. We always selected the early game song and the final battle music from the same game, and chose to look at five games for each cluster. Thus, we had 20 unique songs across 10 games, which were mapped into four clusters depicted in Figure 1.

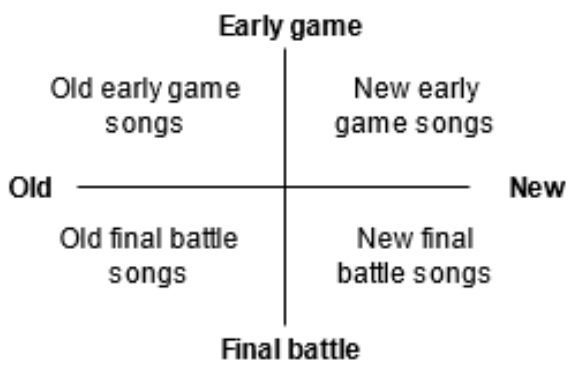

Figure 1. The four dimensions measured in this study.

\subsection{Selection of the songs}

The selection of the songs was driven by three criteria: (1) the songs had to be available on YouTube; (2) the songs had to have a sufficient number of comments (min. 30, preferably 100); and (3) the song had to appear in a popular game so that the authors were aware of it. Following these criteria for the older adventure game cluster (1996-2004) we selected three Pokémon games: (1) Pokémon Red/Blue; (2) Pokémon Silver/Gold; and (3) Pokémon Ruby/Sapphire. This gave us a comparison setup of games within the same franchise. Subsequently, we chose to look at a similar game but from another franchise, (4) Golden Sun. In 2004 Pokémon Red/Blue were remade with better graphics and sound. This offered an opportunity to look at comments to the same songs but with a different mix and possibly associations. Thus, the final game for this cluster was selected to be (5) Pokémon Fire Red/Leaf Green. The early game songs of this cluster are shown in Table 1 and the final battle themes in Table 2.

For the newer adventure game clusters (2015-2019), we selected two Pokémon games: (6) Pokémon Ultra 


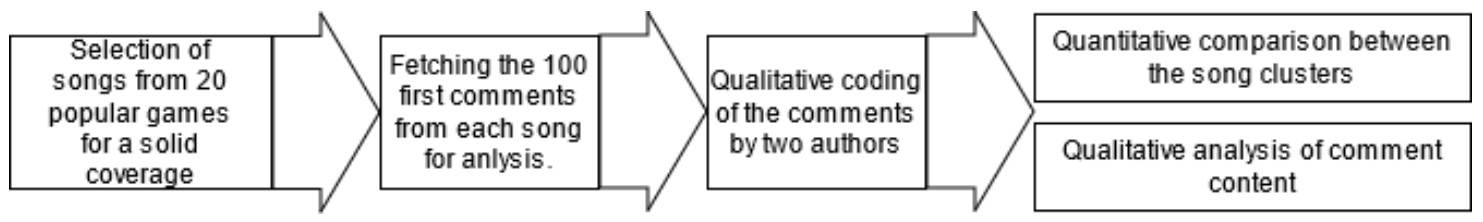

Figure 2. The overview of the research process.

Table 1. Analysed early game songs in old (1996-2002) and new (2015-2021) games.

\begin{tabular}{lcc}
\hline Song name & Release year & No. of views \\
\hline 1. Pallet town & 1996 & $1,25 \mathrm{M}$ \\
2. New Bark town & 1999 & $558 \mathrm{k}$ \\
3. Vale theme & 2001 & $58 \mathrm{k}$ \\
4. Littleroot town & 2002 & $520 \mathrm{k}$ \\
5. Pallet FireRed & 2004 & $199 \mathrm{k}$ \\
\hline 6. Home & 2015 & $7,26 \mathrm{M}$ \\
7. Iki Town & 2017 & $30 \mathrm{k}$ \\
8. BotW theme & 2017 & $2,98 \mathrm{M}$ \\
9. Fossil Falls & 2017 & $1,14 \mathrm{M}$ \\
10. Postwick town & 2019 & $242 \mathrm{k}$ \\
\hline
\end{tabular}

Sun/Moon released in 2017; and (7) Pokémon Sword and Shield released in 2019. We supported the list with two adventure games from the same era for Nintendo consoles: (8) The Legend of Zelda: Breath of the Wild; and (9) Super Mario Odyssey. Finally, we decided to look at a popular similar indie game: (10) Undertale. The final battle songs in this analysis are summarized in Table 1 and Table 2. The ten games are all released on the handheld gaming devices by Nintendo: Gameboy (1), Gameboy Color (2), Gameboy Advance $(3,4,5)$, Nintendo 3DS (6) and Nintendo Switch $(7,8,9,10)$.

\subsection{Data sources - YouTube}

We fetched the top 100 comments on each of the 20 songs from the YouTube comment section. Gathering open online data has the benefit over surveys and interviews that there is no research setting influencing and exerting bias to the data [14]. Instead, open online data can capture users' authentic reactions [15]. The YouTube comment section has been deemed a fairly reliable source of information, although not representative of the global population [16].

The songs were searched with YouTube's search bar using the following string: name of the song + "theme/song/music/soundtrack/OST. We selected the song with most views among the original songs. Remixes and remakes were excluded. The search was carried out in May 2021 by two authors. In all songs the first 100 comments sorted by "top" were read, excluding
Table 2. Analysed late game songs in old (1996-2002) and new (2015-2021) games.

\begin{tabular}{lcc}
\hline Song name & Release year & No. of views \\
\hline 1. Champion Rival & 1996 & $929 \mathrm{k}$ \\
2. Champion Lance & 1999 & $1,17 \mathrm{M}$ \\
3. Champion Steven & 2001 & $968 \mathrm{k}$ \\
4. Doom Dragon & 2001 & $186 \mathrm{kk}$ \\
5. Champion FireRed & 2004 & $2,79 \mathrm{M}$ \\
\hline 6. Megalovania & 2015 & $63,15 \mathrm{M}$ \\
7. Ultra Necrozma & 2017 & $10,97 \mathrm{M}$ \\
8. Dark Beast Ganon & 2017 & $1,81 \mathrm{M}$ \\
9. Bowser Battle 2 & 2017 & $210 \mathrm{k}$ \\
10. Leon Battle & 2019 & $2,81 \mathrm{M}$ \\
\hline
\end{tabular}

replies. In two songs (Vale, Iki Town) there were less than 100 comments. This resulted in the final dataset of $\mathrm{N}=1893$ comments for analysis.

\subsection{Familiarization with the songs and games}

Familiarization with the songs and games was carried out to ensure the authors understood the comments and their nuances. Regarding the games, at least one of the authors had fully completed them. For this particular study, we played the games again to ensure we understood the central game mechanics, narrative elements and musical direction of the games.

In order to understand the musical characteristics of the songs in Table 1 and Table 2, the first author created tool-assisted transcriptions of the songs with the help of Chordify ${ }^{1}$. We focused on three key elements in the songs: (1) the overall structure; (2) melody, chords and tempo; and (3) the voices.

Out of the four sectors in Figure 1, the top left sector had most similarities between the songs in terms of the three elements we focused on. In this cluster all songs were in major key and structure-wise largely similar. The only exception was Vale theme which deviated from the standard major scale and used chromatically descending chords in the middle section among other creative approaches. The early game songs in the newer cluster (2015-2019) were more varied and also had more

\footnotetext{
${ }^{1}$ https://chordify.net/ a proprietary system for automatically identifying melody and chords for songs
} 
instruments and more complex backgrounds to support the main melodies. Tempo-wise the songs were all slow-mid tempo. For example, Pallet town was exactly 120 beats per minute (bpm) and mostly used quarter notes with some half notes. New bark town was slower (85 bpm) but otherwise similar. Littleroot town sat somewhere between the two at around $100 \mathrm{bpm}$. Out of the newer songs the main deviation was the Fossil Falls theme which was at roughly $150 \mathrm{bpm}$.

In comparison to the early game songs, the final boss songs were systematically faster and more complex. The light voices of the early game songs were replaced with darker and sharper tones. The songs were often atonal, and with the exceptions of Ultra Necrozma contained chromatic passages and rarely settled to strictly follow established musical scales. Megalovania mostly follows a diminished minor scale, but also contains some chromatic descending notes towards the end. Altogether, we summarize the differences between early game and late game songs in our sample with the following three points.

- The melodic and rhythmic structures of early game songs are typically fairly simple.

- The final battle themes are generally speaking faster than early game songs with more complex melodic and rhythmic structures.

- The tone color of early game songs is lighter than that of final boss battle music.

\subsection{Comment Coding and Analysis}

We performed qualitative coding, clustering and synthesis of YouTube comments under each of the selected videos. We followed the open coding by Strauss and Corbin [17] and assigned basic codes to the comment data. To remain objective, we avoided interpretation of the comments and tried to pick up the sentiments from concrete wordings used by the participants. We then connected the words to overall sentiment concepts. These concepts, associated codes and examples from the data are given in Table 3. In addition, we looked for what topics the comments focused on following three broad categories: (1) the game; (2) real life; and (3) the song itself.

In the analysis several comments had multiple codes. In theses cases all unique codes were recorded, but a code was recorded only once per comment even if it appeared multiple times. Some of the shorter comments did not contain any codes. These were, for example, comments on the number of views the song video had. The overall proportion of comments with zero quotes was small, ranging from 0-5 comments per song. The coding was performed by two authors. The first song was coded together after which the authors proceeded to work independently. In addition, a song outside the 20 songs (Pokémon Red, Route 11) was chosen to calculate inter-rater reliability [18]. The author's independently went through the first 20 top voted comments of the song and compared their agreement on each comment. A Cohen's Kappa value of 0.73 was obtained, which can be considered substantial agreement [18]. We noticed that simple and short comments often had full agreements while longer comments, or comments containing implicit references (e.g. "that art, that damned art") resulted in disagreement.

We subsequently combined the frequencies of sentiments for each of the four sectors of games. We did comparison at two levels: (1) differences between songs in each individual game; and (2) differences between the clusters of songs. Furthermore, we conducted analysis of the content of the comments and discussed the quantitatively observed key differences between the clusters in further detail.

\section{Findings}

\subsection{Early game songs in old games}

The findings of the coding of the comments on the early game songs of old games (1996-2005) are displayed in Table 4. Among the sentiment categories, nostalgia was most frequent in all theme songs and subsequently the most frequent category of all $(n=206)$. It was followed in frequency by sadness $(n=82)$ and comfort $(n=68)$. With regards to the topics of discussion, most comments related to the game in some way $(n=113)$ followed up by comments on the participants' real life situation $(n=87)$. Surprisingly, very few participants altogether discussed the song itself $(n=36)$. This indicates that the participants were more inclined to share on social media their associations to the songs rather than their opinions about the songs themselves.

4.1.1. Nostalgia The identified codes and related concepts sometimes appeared in comments together. In particular, there was an observable connection between nostalgia and sadness. This was present in several comments across the five songs. Exemplar quotes included the following:

jamul toussaint: "my eyes why wont they stop crying, oh man so much nostalgia". Danish Rahim: "Nostalgia is bittersweet" Matthew Ellis: "The nostalgia! It burns my eyes!"

Comments also combined nostalgia often with 
Table 3. Codes, concepts and examples used in the analysis

\begin{tabular}{|c|c|c|}
\hline Concept & Codes & Examples from the data \\
\hline Nostalgia & nostalgia, flashback, memory, reminiscing & $\begin{array}{l}\text { "Good ol' days" "I miss those times so much" } \\
\text { "I'm getting flashbacks (-)" }\end{array}$ \\
\hline Sadness & sad, cry, separation, detachment & $\begin{array}{l}\text { "I tear up every time I hear this." } \\
\text { "makes me wanna cry" }\end{array}$ \\
\hline Comfort & comfort, soothing, calming, relaxing, peaceful & $\begin{array}{l}\text { "Sounds like home" "Wow, how soothing." } \\
\text { "Like a warm blanket" }\end{array}$ \\
\hline Attachment & belong, connect, link, in love, attach & "I love this song!" "Vale is where I belong" \\
\hline Appreciation & $\begin{array}{l}\text { appreciate, beautiful, stunning, dazzling } \\
\text { greatest, best, favourite }\end{array}$ & $\begin{array}{l}\text { "so beautiful" "(-) makes me appreciate life." } \\
\text { "One of my absolute favorite boss battle themes" }\end{array}$ \\
\hline Joy & joy, happiness, delight & "Hearing the song makes me so happy (-)" \\
\hline Cool & cool,epic, awesome & "This is so cool!","Simply awesome" \\
\hline
\end{tabular}

Table 4. Frequency of sentiments in comments on early songs in old games (from 1996-2005) as well as the topic of the comment if it existed.

\begin{tabular}{|c|c|c|c|c|c|c|}
\hline & 1. Pallet town & 2. New Bark town & 3. Vale & 4. Littleroot & 5. Pallet FireRed & Cumulative \\
\hline No. of comments & 100 & 100 & 59 & 100 & 100 & 459 \\
\hline Nostalgia & 41 & 45 & 13 & 50 & 47 & 206 \\
\hline Sadness & 15 & 26 & 6 & 19 & 16 & 82 \\
\hline Comfort & 13 & 16 & 11 & 20 & 11 & 68 \\
\hline Attachment & 8 & 8 & 3 & 8 & 3 & 30 \\
\hline Appreciation & 9 & 5 & 1 & 6 & 4 & 25 \\
\hline Joy & 10 & 5 & 1 & 5 & 3 & 24 \\
\hline Cool & 1 & 1 & 2 & 0 & 1 & 5 \\
\hline Topic game & 26 & 23 & 14 & 28 & 22 & 113 \\
\hline Topic life & 25 & 22 & 10 & 19 & 11 & 87 \\
\hline Topic song & 6 & 4 & 12 & 5 & 9 & 36 \\
\hline
\end{tabular}

memories of their own life or memories of them playing the game. Surprisingly, several of these comments also included a bittersweet tone. For example, user Jun Yoon commented:

"When my childhood grandfather lived in America gave this Game now grandfather dead but he give my childhood supreme presents "Golden sun"”

Furthermore, several users discussed their early childhood without explicit reference to nostalgia. As an example, user Isaac Ling wrote:

"ah i miss the ol' simple days, where there wasn't as many things to worry about".

This comment also connects to the idea of being free of worry and feeling relaxed, which was the second major overarching theme in the comments of the early game songs of old games.

4.1.2. Comfort The comments relating to comfort, calmness, relaxation and peace consisted of slightly more than $1 / 7$ of all comments in this cluster, which can be considered substantial. A major proportion of these comments directly discussed home or a sense of being home. Three exemplar quotes are given below, which were also heavily liked with $1.5 \mathrm{k}, 2.5 \mathrm{k}$ and $1.3 \mathrm{k}$ likes respectively:

StylesX2: "home" astrobat: "Sounds like home..." SB190 46 Irfan: My life is a mess right now but this... This takes me home

The mentioned reasons why these early game songs invoked the feeling of "home" in players could be broadly divided into three categories: (1) in-game reasons; (2) memories of a worry-free childhood; and (3) the song itself. With regards to the first category, given reasons in the comments included that the player starts from the place where the song plays and embarks on an adventure. The home remains a safe and happy place where players felt peaceful to return to. Furthermore, in all of the games the players" "mom" character was associated with the song. Example quotes of the in-game reasons are given blow:

the scrub: " $i$ wish Vale was real and $i$ could live there" kether: "I used to go back to Vale just to listen to it, and I fell asleep everytime with the gba in my hands haha.. So calm and peaceful, cant get tired of it."

With regards to the second category, the comments 
likened the song to a time in the commentators life where everything was well. For example, user ryan jansen stated:

"Almost 17 years now my friends! But hearing this will always take me back to 2004 when life was much simpler and innocent for me"

The songs themselves were also perceived peaceful as expressed by some users. In fact, all of the early game songs were similar in that they were slow or mid tempo, were relatively simple harmony-wise and were written in a major scale. Comments on the songs themselves noted this as well. Two exemplar quotes are given below:

ImRealKrish15: "I dont have nostalgia stories or anything but hearing this make my mind in peace no stress about homework, future and stuff like absolute peace" RandomStranger_3: "a piece of music that lulls you to peace, trainquility and serenity."

Finally, interestingly, the on-going COVID-19 pandemic was also brought into discussion where participants discussed how the early game songs could help them find hope and peace in the troubling times. For example, user Daniel Majzoub stated:

"The world is falling apart, life's getting tough, this is one of the few things that give me comfort, thank you Hoenn"

\subsection{Early game songs in new games}

The findings of the early game songs in new games are depicted in Table 5. Similarly to the early game songs in old games, nostalgia was the most often appearing category $(n=79)$ even though it appeared less often. In this cluster the discussion most heavily revolved around the song $(n=116)$ which was over 3 times as often as in the early game songs of older games. Content-wise the comments also differed between the two clusters, in particular with regards to nostalgia and comfort.

4.2.1. Nostalgia The nostalgia comments appeared most often in Fossil Falls $(n=33)$ and Postwick theme $(n=24)$. These were also the only two songs from this category where nostalgia was the most often mentioned sentiment category. Contrasting the previous cluster, here comments often discussed nostalgia at a meta-level, remarking, for example, how little time it took the participants to develop nostalgic feelings towards the song. Examples of these types of comments are given below:

blayedd: "It hasn't even been 2 years and this already gives me nostalgia" Kris Adam: "Kids who play this game today, will probably have nostalgia just by hearing this 10 years later."

In some comments it was unclear whether the participants were joking, feeling nostalgia or using the word nostalgia in a very broad sense. For example, participants stated they were nostalgic about the early game song after finishing the game, and in a few instances, only after moving to the next town in the game. Exemplar quotes are given below:

PrxjectFloof: "The fricking nostalgia when u finish the game" Moe fox: "I just got Shield yesterday, I just got past the first gym, but this is already nostalgic." Bepis Boy: "Never before have I felt nostalgia for a game that's not even out yet."

While in the previous category nostalgia was associated with sadness and plaintive feelings, in the newer games such a connection was more rare. Instead, sadness was associated to the songs themselves and the way they sounded. Altogether the songs themselves were discussed more often than associations to the songs. For example, user Pimp commented under the BotW theme:

"its almost been two years... and this theme never fails to get at least one tear from me, just from how beautiful this theme is."

Finally, some nostalgic comments were related to how impactful and memorable the games were. In these comments there was the implicit notion that nostalgic songs made players appreciate the game more, and remember it better. This was also shown in the appreciation category comments $(n=47)$. An example comment that included the codes of appreciation and nostalgia comes from user nevermind12:

"It hasn't even been a year since the game came out and I'm already nostalgic about it. Game Freak is hiding something from us. How can they make such memorable games?"

4.2.2. Comfort Roughly $1 / 9$ of the comments $(n=52)$ were related to comfort, relaxation and the feeling of home. However, more than half of these comments were from the song Home from Undertale. Most comments here focused on a single in-game character (Tauriel) associated with the theme. Such strong associations were not present in the other observed songs. In the other songs, there were comments stating how the song managed to relieve stress and help them relax. For example, Bella Banana commented: "Depression: Cured; Anxiety: Cured; Stress: Gone"

If we do not consider the anomaly song Home for the comfort-category, we see that there were significantly 
Table 5. Frequency of sentiments in comments on early songs in new games (from 2015-2021) as well as the topic of the comment if it existed.

\begin{tabular}{lcccccc}
\hline & 6. Home & 7. Iki Town & 8. BotW theme & 9. Fossil Falls & 10. Postwick & Cumulative \\
\hline No. of comments & 100 & 34 & 100 & 100 & 100 & 434 \\
\hline Nostalgia & 7 & 7 & 8 & 33 & 24 & 79 \\
Sadness & 15 & 6 & 21 & 16 & 11 & 69 \\
Comfort & 33 & 7 & 0 & 8 & 4 & 52 \\
Attachment & 4 & 8 & 2 & 4 & 3 & 21 \\
Joy & 2 & 1 & 7 & 10 & 2 & 22 \\
Appreciation & 8 & 0 & 18 & 4 & 17 & 47 \\
Cool & 0 & 0 & 2 & 10 & 2 & 14 \\
\hline Topic game & 31 & 4 & 26 & 18 & 17 & 96 \\
Topic life & 9 & 1 & 7 & 19 & 10 & 46 \\
Topic song & 14 & 3 & 33 & 25 & 41 & 116 \\
\hline
\end{tabular}

less comments related to comfort among the newer game songs than the older game songs. One of the explanations for this is that comments relating to childhood and simpler times were missing from the newer games' comment sections. Thus, we can postulate based on the data that one crucial factor contributing to a song sounding relaxing, peaceful and calm is that it was listened to during childhood. A final interesting remark with regards to the early game songs in newer games comes from YouTube user Justin Arney:

"This song isn't meant for when you start your journey its for when you return and remember how far you've come"

This implies that the home town theme is able to capture a sense of adventure by setting a comparison point for the players. After listening to the music during the early stages of playing, players then go on an adventure and experience hurdles and struggles orchestrated by a myriad of songs and compositions. When after an adventure they return home, they hear the simple and joyful home town song and realize the adventure they had.

\subsection{Final battle themes in old games}

The frequency of appearance of the codes in the final battle themes of old games are displayed in Table 6 . The key difference here compared to the early game songs is that appreciation $(n=52)$ was the most frequent sentiment category. Nostalgia $(n=42)$ appeared less often than in the early game songs of old games $(n=206)$ and even new games $(n=79)$. This implies that the age of the game may have less impact on whether players develop nostalgic feelings towards the song compared to other factors. Another noticeable difference is that the participants were overwhelmingly more commenting on in-game events $(n=285)$ compared to the other topic categories.

4.3.1. Comments related to the game A significant proportion of the comments $(n=285)$ were related to in-game events in one form or another. This included game content-related memes (e.g., trumpets in Ruby/Sapphire) and direct quotations of game dialogue. Interestingly, while comments in the "cool" category did not appear often $(n=17)$, these comments received thousands of likes. Exemplar quotes are given below:

Federico Moreira: "Your rival as champion is just epic", 6.3k likes Andreas Rask: "Probably the greatest and most epic soundtrack in Pokémon history, compared to its age and what handheld console it was for." $1.6 \mathrm{k}$ likes Trashley: "What was cooler? Seeing your rival as champion in gen 1, or seeing yourself as champion in gen 2 ?" $5 \mathrm{k}$ likes

4.3.2. Absence of comfort Notably the comfort sentiment was featured in zero comments out of all 500 that were coded for this cluster. During the familiarization phase to the game's and the music, we noticed that there are key distinct musical differences between the songs in addition to their in-game associations. We argue that these two are the two main factors contributing to the complete omission of the comfort category. Supporting the argument that the music itself plays a major part is, that the complexity and speed of the final battle songs was noted by multiple participants across all five songs. As an example, on the fast-paced Doom Dragon theme that alternates between the time signatures of 5/8,4/4, 7/8 and 3/4, Jacob Kountz commented:

"I just realized: Golden Sun music reminds me of 
Table 6. Frequency of sentiments in comments on final battle songs in old games (from 1996-2005) as well as the topic of the comment if applicable.

\begin{tabular}{lcccccc}
\hline & 1. Battle! & 2. Lance & 3. Doom Dragon & 4. Steven & 5. Fire Red & Cumulative \\
\hline No. of comments & 100 & 100 & 100 & 100 & 100 & 500 \\
\hline Nostalgia & 11 & 8 & 6 & 9 & 8 & 42 \\
Sadness & 1 & 1 & 7 & 0 & 0 & 9 \\
Comfort & 0 & 0 & 0 & 0 & 0 & 0 \\
Attachment & 1 & 1 & 0 & 0 & 5 & 7 \\
Joy & 0 & 0 & 1 & 0 & 1 & 2 \\
Appreciation & 6 & 4 & 8 & 12 & 22 & 52 \\
Cool & 0 & 1 & 6 & 1 & 9 & 17 \\
\hline Topic game & 49 & 66 & 58 & 53 & 59 & 285 \\
Topic life & 12 & 6 & 12 & 6 & 2 & 38 \\
Topic song & 15 & 15 & 21 & 22 & 33 & 106 \\
\hline
\end{tabular}

Dream Theater! ${ }^{2}$,

\subsection{Final battle themes in new games}

The results of coding the comments of the final battle themes in the newer games cluster are displayed in Table 7. The results are similar to the findings from final battle themes in old games with two exceptions: (1) there are less nostalgia comments (8 compared to 42); and (2) there are slightly more comments focusing on the song (170 compared to 106). Between the songs the sentiment frequencies were even. However, there were differences, in particular, in how often the comments referenced real life. In this regard, Megalovania was different from the rest of the songs. The differences may be explained by Megalovania being hugely popular (the most popular song among the 20 focused songs) and part of online culture beyond gaming. Two exemplar quotes are given below.

Ark Shrivastava: "We did it boys, Megalovania is a culture" Pitbull fella: "Megalovania isn't just a song. It's a genre of music on itself."

4.4.1. Comments related to the game Similarly to the cluster of final battles in old games, comments were focused on in-game events and the experiences players had with the boss fights. The comments also featured game-specific terminology. For example, the comments for the Ultra Necrozma Battle Music often referred to on the in-game battle and how difficult it is. As an example, PlasmaZMB commented:

"Its missing the sound of all of my pokémon being outsped and one shot"

Based on the comments, the battle against Ultra Necrozma seems to be impactful for players largely due

\footnotetext{
${ }^{2}$ Dream Theater is an American band known for complex rhythms and fast playing.
}

to its difficulty. The in-game experience may partially explain the enormous number of plays the theme has on YouTube (almost 11 million). Another similar song was Megalovania where the difficulty of the battle was also references multiple times. Contrasting the difficult boss battles, Dark Beast Ganon battle music received comments on how easy the battle was. User DeDHeD 81 humoristically commented on this while giving credit to the song:

"This is the toughest boss because if you beat him, you stop the music"

The Dark Beast Ganon music comment section also contained multiple instances of the exact same quote from the Breath of the Wild that also appeared in the early game song of the game: "courage need not be remembered, for it is never forgotten".

4.4.2. Appreciation In this cluster of songs there were cumulatively most appreciation comments $(n=62)$ compared to the other three clusters. These comments were mostly directed towards the song. Sometimes the comments were straightforward. For example, Aperson stated on the Bowser Battle 2 song:

"This is already one of the greatest Final Boss themes of all time."

Some comments were focused specifically on the feelings that arise from the song or the boss battle. These comments typically featured other emotions besides appreciation such as coolness or joy. Exemplar quotes are given below:

NinjaKiwi2903: "Am I the only one who thinks 0:50 is the best part? It just feels romantic mixed with hate which fits perfectly to this battle!" Caz: "This song is like every badass boss fight you've conquered in every video game you've ever played, concentrated into an IV, and pumped into your bloodstream" 
Table 7. Frequency of sentiments in comments on late game songs (final battle music) in new games (from 2015-2021) as well as the topic of the comment if applicable.

\begin{tabular}{lcccccc}
\hline & 6. Megalovania & 7. Necrozma & 8. DB Ganon & 9. Bowser Battle 2 & 10. Leon & Cumulative \\
\hline No. of comments & 100 & 100 & 100 & 100 & 100 & 500 \\
\hline Nostalgia & 1 & 1 & 1 & 2 & 4 & 8 \\
Sadness & 1 & 1 & 2 & 0 & 6 & 9 \\
Comfort & 0 & 0 & 0 & 0 & 1 & 1 \\
Attachment & 0 & 0 & 0 & 5 & 3 & 8 \\
Joy & 0 & 0 & 2 & 0 & 2 & 4 \\
Appreciation & 2 & 19 & 13 & 12 & 16 & 62 \\
Cool & 3 & 2 & 6 & 2 & 2 & 15 \\
\hline Topic game & 22 & 62 & 58 & 42 & 70 & 254 \\
Topic life & 30 & 1 & 7 & 0 & 2 & 40 \\
Topic song & 41 & 26 & 32 & 43 & 28 & 170 \\
\hline
\end{tabular}

This cluster had the most comments $(n=170)$ discussing the song itself out of all four clusters. The comments were exclusively positive, which can be explained by two factors: (1) people seeking out the songs have a predisposition to like them; and (2) the top comments in a video are filtered by the community through liking and disliking. An example of a comment on the song that was not assigned a sentiment code comes from user DeadJosey:

"this is still a banger I dont care".

\section{Discussion}

\subsection{Key Findings}

Regarding RQ1, we noticed that across all four clusters of songs there were overwhelmingly more comments focusing on the game $(n=721)$ than on the songs $(n=428)$. The comments featured various sentiments from sadness, which was often related to nostalgia, to joy and appreciation.

For RQ2 and RQ3 we present the following key findings. First, nostalgia appeared as a major theme in the early game songs of old games (45\% of comments), but less so in early game songs of new games (18\%) and final battle themes of old games (8\%). This confirms there are other significant factors influencing the development of nostalgic feelings towards video game music besides the age of the game, including where in the game the song plays. Second, comments showed that early game songs were associated with feelings of comfort while final boss battles were not. An analysis of the comments themselves revealed three explanations for this: (1) in-game associations; (2) the music; and (3) situation-in-life associations i.e. memories of childhood. Third, final battle music featured significantly more comments related to the game (54\%) compared to early game songs (23\%). This finding supports the hypothesis that final boss songs are experienced heavily in the context of the in-game situation they appear in, even if listened outside the game context on YouTube.

Among the other findings we pinpoint that we found evidence that nostalgia may emerge quickly even during a single playthrough of a game. Players expressed to have experienced nostalgic feelings upon returning to the home town in-game where their adventure began. Furthermore, nostalgia often appeared with the sentiment of sadness, implying a plaintive approach to nostalgia. Previous work has stated that when people are asked to remember nostalgic experiences they tend to associate them with positive feelings, but when life events trigger nostalgia, it is more often associated with negative sentiment [19]. While in our case YouTube users obviously sought out the songs themselves and chose to comment on them, the association with negative emotion was present. This finding can be of interest for the research on nostalgia generally [19] and for research of video game nostalgia in particular [20,5]. Finally, there was not much variance across comments in early game songs nor across final battle songs, but there was substantial variance between early game songs and final battle songs.

\subsection{Limitations}

In this work, we focused on music in adventure games, meaning the findings may not apply to other types of games. In addition, there are three key limitations in our empirical research which have to be considered.

First, people who seek out specific songs on YouTube and bother to comment and like comments most likely have an emotional predisposition to like the 
song. This may partially explain the overwhelmingly positive comments which all songs received. Thus, the findings should not be considered representative of the entire player population. Second, we selected YouTube comments for analysis based on sorting by top voted comments. However, there may be several reasons a comment is ranked popular by the YouTube recommender system, all of which may not accurately reflect the sentiments and perceptions of the player population. Accordingly, this may have introduced some bias to the collection of quotes selected for analysis. Third, as in all qualitative work, the authors' own predispositions influenced the interpretation of the comments and the coding process.

\section{Conclusions and future work}

We discovered quantitative differences in sentiments and topics of comments on video game music between four clusters. While the qualitative analysis of the comments provided insights regarding the quantitative findings, future research on how games influence associations to specific songs, and how strong these associations are, is needed. Due to the reported complexity of influence of video game music $[13,10]$ empirical studies in particular are valuable, as a plethora of empirical evidence can inductive reasoning aiming for more universal theoretical frameworks.

Music remains an important component of adventure video games. Popular video games have soundtracks which people voluntarily look up on YouTube and other similar platforms and spend time listening to and commenting on. In our sample only $23 \%$ of the comments discussed the song, and a significantly larger portion of comments $(38 \%)$ focused on the game where the song plays. The comments showed that video game music reminded players of specific instances of their gaming experience, but also of real world situations and the time in their life when they played the game.

\section{Acknowledgements}

This work was supported by Academy of Finland Flagship Programme under Grant No. 337653 (Forest-Human-Machine Interplay (UNITE)).

\section{References}

[1] Z. Whalen, "Play along-an approach to videogame music," Game studies, vol. 4, no. 1, p. 214, 2004.

[2] G. Hooper, "Sounding the story: Music in videogame cutscenes," in Emotion in video game soundtracking, pp. 115-141, Springer, 2018.

[3] C. Klimmt, D. Possler, N. May, H. Auge, L. Wanjek, and A.-L. Wolf, "Effects of soundtrack music on the video game experience," Media Psychology, vol. 22, no. 5, pp. 689-713, 2019.

[4] R. Daneels, H. Vandebosch, and M. Walrave, ““'just for fun?": An exploration of digital games' potential for eudaimonic media experiences among flemish adolescents," Journal of Children and Media, vol. 14, no. 3, pp. 285-301, 2020.

[5] T. Wulf, N. D. Bowman, J. A. Velez, and J. Breuer, "Once upon a game: Exploring video game nostalgia and its impact on well-being.," Psychology of Popular Media, vol. 9, no. 1, p. 83, 2020

[6] F. S. Barrett, K. J. Grimm, R. W. Robins, T. Wildschut, C. Sedikides, and P. Janata, "Music-evoked nostalgia: affect, memory, and personality.," Emotion, vol. 10, no. 3, p. 390, 2010.

[7] S. A. Mehr, M. Singh, D. Knox, D. M. Ketter, D. Pickens-Jones, S. Atwood, C. Lucas, N. Jacoby, A. A. Egner, E. J. Hopkins, et al., "Universality and diversity in human song," Science, vol. 366, no. 6468, 2019.

[8] K. Vella, D. Johnson, V. W. S. Cheng, T. Davenport, J. Mitchell, M. Klarkowski, and C. Phillips, "A sense of belonging: Pokémon go and social connectedness," Games and Culture, vol. 14, no. 6, pp. 583-603, 2019.

[9] S. Laato, S. Rauti, A. N. Islam, and E. Sutinen, "Why playing augmented reality games feels meaningful to players? the roles of imagination and social experience," Computers in Human Behavior, p. 106816, 2021.

[10] T. Summers, Understanding video game music. Cambridge University Press, 2016.

[11] M. Fritsch, "History of video game music," in Music and game, pp. 11-40, Springer, 2013.

[12] I. Hart, "Meaningful play: Performativity, interactivity and semiotics in video game music," Musicology Australia, vol. 36, no. 2, pp. 273-290, 2014.

[13] Z. Whalen, "Case study: Film music vs. video-game music: The case of silent hill," Music, sound and multimedia: from the live to the virtual, pp. 68-84, 2007.

[14] D. Parry, B. Davidson, C. Sewall, J. Fisher, H. Mieczkowski, and D. Quintana, "A systematic review and meta-analysis of discrepancies between logged and self-reported digital media use," Nature Human Behavior, 2021.

[15] S. Laato, N. Inaba, M. Paloheimo, and T. D. Laajala, "Group polarisation among location-based game players: an analysis of use and attitudes towards game slang," Internet Research, 2021.

[16] I. Dubovi and I. Tabak, "An empirical analysis of knowledge co-construction in youtube comments," Computers \& Education, vol. 156, p. 103939, 2020.

[17] A. Strauss and J. Corbin, Basics of qualitative research techniques. Citeseer, 1998.

[18] B. B. Frey, The SAGE encyclopedia of educational research, measurement, and evaluation. Sage Publications, 2018.

[19] D. B. Newman, M. E. Sachs, A. A. Stone, and N. Schwarz, "Nostalgia and well-being in daily life: An ecological validity perspective.," Journal of personality and social psychology, vol. 118, no. 2, p. 325, 2020.

[20] T. Wulf, N. D. Bowman, D. Rieger, J. A. Velez, and J. Breuer, "Video games as time machines: Video game nostalgia and the success of retro gaming," Media and Communication, no. 2, pp. 60-68, 2018. 